\title{
IMMOBILIZATION OF COLD-RESISTANT MIXED BACTERIA AND ITS APPLICATION IN SEQUENCING BATCH REACTOR WASTEWATER TREATMENT
}

\author{
YANG, Y. W. ${ }^{1}-$ DUAN, X. Y. ${ }^{2}-$ JIANG, J. ${ }^{1}-$ XU, X. Y. ${ }^{1}-$ TANG, M. Z. ${ }^{*}$ \\ ${ }^{1}$ Key Laboratory of Nasihu Lake Wetland Ecosystem \& Environment Protection, Qufu Normal \\ University, Qufu, Shandong, China \\ (e-mail: yangyuewei@163.com (Yang, Y.W.),naruto4869@163.com (Jiang, J.), \\ Xuxiaoyan32112@163.com (Xu, X. Y.); phone: +86-136-7547-8229) \\ ${ }^{2}$ Nankai University, Tianjin, China \\ (e-mail:479828612@qq.com; phone: +86-185-2632-9818) \\ ${ }^{*}$ Corresponding author \\ e-mail:qsd_tmzh@qfnu.edu.cn
}

(Received $28^{\text {th }}$ Sep 2019; accepted $4^{\text {th }}$ Dec 2019)

\begin{abstract}
Immobilized microbial degradation technology has the advantages of simple solid-liquid separation, strong toxicity resistance, and low sludge yield. This study creatively added biochar to the immobilized microbial activated pellets and optimized the immobilization conditions for these pellets. This experiment also studied the removal efficiency of chemical oxygen demand (COD), total phosphorus (TP), ammonia nitrogen $\left(\mathrm{NH}_{3}-\mathrm{N}\right)$ and total nitrogen $(\mathrm{TN})$ for immobilized microbial pellets in the SBR (Sequencing Batch Reactor) with different dosages and hydraulic retention time (HRT). Results showed that the optimal conditions were reached when: the mass fraction of SA (sodium alginate) was $2 \%$, the amount of PVA (polyvinyl alcohol) was $4 \%$, and cross-linking time $24 \mathrm{~h}$, the best biochar added was RS700. Mixed bacteria under the condition of the optimization system for immobilized pellets were added to the continuously running of SBR process, $20 \mathrm{~mL}$ bacteria suspension of immobilized pellets could be used to test the best dosage through the experiment monitoring. In a comprehensive consideration, the optimal HRT was $4 \mathrm{~d}$, and the removal efficiency of $\mathrm{COD}, \mathrm{TP}, \mathrm{NH}_{3}-\mathrm{N}$ and TN under the best dosage was reached at $76.79 \%, 56.50 \%, 67.60 \%$ and $54.92 \%$ at 4 days, respectively. In the SBR process, the degradation efficiency of immobilized pellets for each pollutant COD, TP, $\mathrm{NH}_{3}-\mathrm{N}$ and TN in the SBR conforms to the first-order kinetic model.
\end{abstract}

Keywords: immobilized microbial pellets, SBR, first-order kinetic model, biochar, sewage treatment

\section{Introduction}

The research on cold-resistant bacteria in China is relatively new, which has attracted extensive attention. It wasn't until the 1990s that people had a systematic understanding of the cold-resistant bacteria in the past century. The rate of contaminant biodegradation by cold-resistant bacteria at low temperature was also explored at that time (Tang et al., 2018). Psychrotolerant or psychrophilic microorganisms are extremophilic organisms, which can grow and reproduce at the temperatures ranging from $-15^{\circ} \mathrm{C}$ to $+20^{\circ} \mathrm{C}$. The cold-resistant microorganisms can grow from $0^{\circ} \mathrm{C}$ to $40^{\circ} \mathrm{C}$, and the optimal temperature is between $20^{\circ} \mathrm{C}$ and $40^{\circ} \mathrm{C}$. However, the psychrophilic microorganisms can grow from $0^{\circ} \mathrm{C}$ to $20^{\circ} \mathrm{C}$ and the optimal temperature is below $15^{\circ} \mathrm{C}$. The environments they inhabit are ubiquitous on earth, as a large fraction of our planetary surface experiences temperatures below $15^{\circ} \mathrm{C}$. Most psychrophiles are bacteria or archaea. They belong to Arthrobacter sp., Psychrobacter sp., members of the genera Halomonas, Pseudomonas, Hyphomonas, and Sphingomonas (Mei et al., 2016). Generally speaking, mixed bacteria refer to the 
mixed bacteria whose dominant strains are combined by measuring the functions of two or more microbial strains. It can be composed of different types of bacteria, such as fungi. It can also be a combination of different types of bacteria, such as bacteria and fungi. Also, it was found that the mixing of strains had better synergistic effect than that of a single strain.

Immobilized microbial degradation technology has been favored for its high density of bacteria, low yield of sludge, strong resistance to toxicity and continuous operation. Through immobilization, microorganisms are fixed on the carrier to maintain a highly dense and bioactive function and to proliferate to adsorb and degrade organic compounds in water under appropriate conditions (Rao and Viraraghavan, 2002; Hachicha et al., 2009). Immobilized microbial degradation technology also has the advantages of keeping the dominant bacteria of high processing efficiency, large amount of biomass, stable operation, easy solid-liquid separation, and low price, etc., which is of great research value in organic wastewater treatment. At present, immobilization technology has been widely used in the practical production of sewage treatment in all walks of life. For example, Liu et al. (2013) have studied the treatment of heavy oil wastewater from the Liaohe oil field of China by using the upper flow anaerobic sludge bed and the fixed biological aeration filter combined biological process. Zhao et al. (2010) used immobilized microorganism technology to treat red water through an aerobic biofilter, and the 2,4,6-nitrotoluene (TNT) was ultimately degraded. For an ideal immobilized microorganism technology, the selection of immobilized carrier is the most important in addition to establishing a highly efficient immobilized reactor and highly efficient and intensive microorganisms with strong resistance. It is of significant importance to find immobilized carriers with stable performance, good mass transfer, high intensity, long life span, and low price (Vázquez et al., 2006). The common carriers for immobilization include natural materials and synthesized materials. There is no doubt that the former has the advantages of lower cost, easy to obtain, and no complicated experimental preparation at earlier stage, which can be widely used in production (Shen and Duvnjak, 2005). In recent years, some agricultural byproducts, such as rice husk, pine bark, peanut shell, sawdust and cork biomass have been used in different kinds of wastewater treatment (He et al., 2019). Straw is the biomass material rich in cellulose, lignin, and other natural polymers (Marshall and Johns, 1996; Gundogdu et al., 2009). Its molecular chains is distributed with a large number of active groups such as hydroxyl and carboxyl groups, which has good complexation, adsorption, and flocculation effects on contaminants in water. At the same time, carboxyl, sulfonic acid group, amino, imino, acylamino, and other groups are good for cell adhesion and proliferation (Van Wyk, 1997; Argun et al., 2009).

Compared with traditional or conventional treatments Sequencing Batch Reactor (SBR) is an easily obtainable, on timescale, highly operational, flexible technology for newer and varied pollutants (Kulkarni, 2013; Dutta and Sarkar, 2015; Popple et al., 2016). The SBR systems have many advantages of lower operational cost, less bulking and higher flexibility to combine nitrification and denitrification phases into one reactor (Lim et al., 2011) with good removal efficiency for nitrogen, phosphorus and chemical oxygen demand (Ding et al., 2011; Popple et al., 2016; Khan et al., 2019; Showkat and Najar, 2019). Microbial degradation plays a dominant role in the removal of soluble/colloidal biodegradable organics in wastewater (Nguyen, 2000; Chen et al., 2017). However, the sewage treatment efficiency of SBR in northern China is rather 
low in winter. This is because microbial activity is decreases as the water temperature decreases, and the biological activity of SBR might decrease under winter conditions. Thereby the pollutant removal efficiency and, more importantly, the efficacy of this contaminant removal technique might be affected by seasonal changes (Tang et al., 2018).

In this study, it creatively added rice straw biochar to the sodium alginate and agar, and finally formed immobilized microbial pellets concluded mixed bacteria. The removal efficiencies of chemical oxygen demand (COD), total phosphorus (TP), ammonianitrogen $\left(\mathrm{NH}_{3}-\mathrm{N}\right)$ and total nitrogen $(\mathrm{TN})$ were measured to test the biotreatment performance of immobilized microbial pellets in the SBR system. The objectives of this study were to: i) prepare and introduce immobilized microbial pellets and optimize the immobilization conditions for immobilized pellets. ii) determine the removal efficiencies of chemical oxygen demand (COD), total phosphorus (TP), ammonianitrogen $\left(\mathrm{NH}_{3}-\mathrm{N}\right)$ and total nitrogen $(\mathrm{TN})$ with immobilized microbial pellets in the SBR. iii) evaluate the effects of different dosages and hydraulic retention time (HRT) with immobilized microbial pellets in the SBR. iii) provide a modelling tool to simulate and evaluate the pollutant removal efficiency of the immobilized microbial pellets. The results of this study provide a theoretical foundation and scientific support for the use of SBR in wastewater treatment, and may have great significance in solving the increasingly severe water pollution problem in China.

\section{Materials and methods}

\section{Enrichment culture, separation, screening, and identification of the mixed Psychrotrophic bacteria species}

The strains including three types of bacteria, used in the experiment, were isolated from the soil samples collected from the constructed wetlands in the Nansihu Lake in Shandong Province, China. Under cold-temperature conditions $\left(6( \pm 2)^{\circ} \mathrm{C}\right)$, Strain 1 was composed of a Gram-positive translucent circular ivory colony, with a moist surface, and regular edge. Strain 4 was a Gram-negative opaque round milky colony with a moist surface, and irregular edge. Strain 5 was a Gram-positive translucent yellow colony with a moist surface and irregular edges. Strains 1, 4 and 5 were all spherical with no flagella. After the strains 1, 4, and 5 were cultured, total DNA was extracted and used as a template. Using Primers 8f (5'AGAGTTTGATCCTGGCTCAG3') 20bp and 1492r (5'GGTTACCTTGTTACGACT-T3') and after cloning and purification, the PCR product was then carried out by Shanghai Biological Engineering Co, Ltd. The 16S rDNA specific sequence of strain 1 was 1498bp (GenBank acceptance number: KR083014), the 16S rDNA specific sequence of strain 4 was 1489bp (GenBank acceptance number: KR083015), and the rDNA specific sequence of strain 5 was 1469bp (GenBank acceptance number: KR083016), after the three strain sequences were analyzed, strain 1 was named Psychrobacter TM-1, strain 4 was named Sphingobacterium TM-2, and strain 5 was named Pseudomonas TM-3. Tang et al. (2018) had produced the phylogenetic tree in our previous research.

The process was repeated three times so that the remaining nutrients could be removed. Finally, the absorbance of the solution was adjusted to 1.2 using normal saline. The bacterial solutions were then mixed together at a volume ratio of 1:1:1 and were placed at $6^{\circ} \mathrm{C}$ for later use. 


\section{Biochar preparation}

The rice straw was collected from Nanquan Village, Qufu Country, Jining City, Shandong Province, China. $20 \mathrm{~g}$ of crushed feedstocks were covered with a fitted lid and pyrolyzed under oxygen-limited conditions in a muffle furnace. The pyrolysis temperature was heated from room temperature to different temperatures $(300,500$ and $700^{\circ} \mathrm{C}$ ) for $3 \mathrm{~h}$, naturally cooled to room temperature, sealed and bottled for use. After treatment with $300 \mathrm{ml}$ of $1 \mathrm{~mol} / \mathrm{L}$ hydrochloric acid for $4 \mathrm{~h}$, the ash substances such as calcium carbonate were removed, and then filtered, washed with distilled water until the washing liquid was neutral, and oven dried at $80^{\circ} \mathrm{C}$ for $24 \mathrm{~h}$. The entire carbonized product was ground and sieved through a 60 -mesh screen, transferred into a plastic bag. The biochar were denoted as RS300, RS500, RS700 (RS stands for rice straw, the number represents carbonization temperature), respectively.

\section{Pellets with immobilized microbials}

Biochar powder, sodium alginate, microbial liquid and polyvinyl alcohol (PVA) was used to prepare the immobilized microbial activated pellets. The preparation process for pellets is presented in Figure 1.

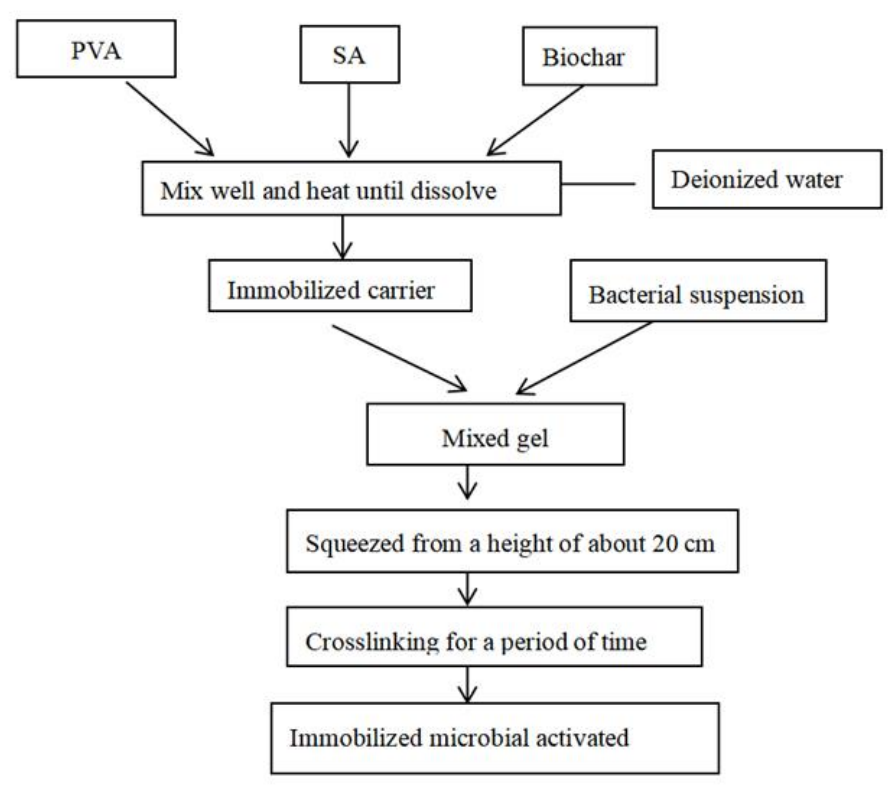

Figure 1. The preparation process of immobilized pellets

Add 4 g polyvinyl alcohol (PVA) to $100 \mathrm{~mL}$ deionized water in a beaker, heat it in water bath at $50-60^{\circ} \mathrm{C}$ until it is evenly dissolved. Then add $2 \mathrm{~g}$ alginic acid sodium (SA) and $0.4 \mathrm{~g}$ biochar as gelling agent after stirring and cooling to room temperature, $20 \mathrm{~mL}$ of the previously treated bacterial suspension was added and mixed well. The crosslinking agents were made by boronic acid, anhydrous calcium chloride and water at $\mathrm{pH}$ 6.5. The mixed gel was dripped to the crosslinking agent by a syringe and squeezed slightly from a height of about $20 \mathrm{~cm}$. And the shape of pellets was naturally spherical, smooth and elastic. To obtain immobilized microbial activated pellets whose particle size $5.0 \mathrm{~mm}$, it was placed at $6-8^{\circ} \mathrm{C}$ in the freezer for the cross-linking for $0,8,16$, 24, 36, and 48 h, respectively (Fu et al., 2018). 
The optimization conditions are set as follows using one-variable-at-a-time approach, various immobilization parameters were optimized by maintaining all factors at a constant level, except the variable under study. To determine the optimum addition amount of PVA, various concentrations of $0 \%, 2 \%, 3 \%, 4 \%$ and $5 \%(\mathrm{w} / \mathrm{v})$ were added to prepare the pellets, respectively, when the amount of SA is fixed at $2 \%$. Similarly, the addition amount of SA was $0 \%, 0.5 \%, 1 \%, 2 \%, 3 \%$, and $4 \%(\mathrm{w} / \mathrm{v})$, respectively, when the PVA was $4 \%$. The cross-linking time was set to $0 \mathrm{~h}, 8 \mathrm{~h}, 16 \mathrm{~h}, 24 \mathrm{~h}$ and $36 \mathrm{~h}$ under the remaining conditions have not changed. For the effect of biochars at different temperature in the study, add RS300, RS500, RS700 $0.4 \mathrm{~g}$ to the system, and the rest of the conditions were unchanged, immobilized pellets without biochar were added as blank controls at the same time, and triplicate for each experiment (Bisht et al., 2013).

\section{Sequencing Batch Reactor (SBR)}

The reactor is made of plexiglass and has a cylindrical shape with a bottom diameter of $15 \mathrm{~cm}$, a column height of $25 \mathrm{~cm}$, a volume of about $3 \mathrm{~L}$, and an effective volume of $2 \mathrm{~L}$. The experimental device was operated by mechanical agitation, and an aerator was placed at the bottom for aeration to control the DO concentration in the reactor during the aeration phase. The schematic diagram of the SBR is shown in Figure 2, and the operating cycle is shown in Table 1.

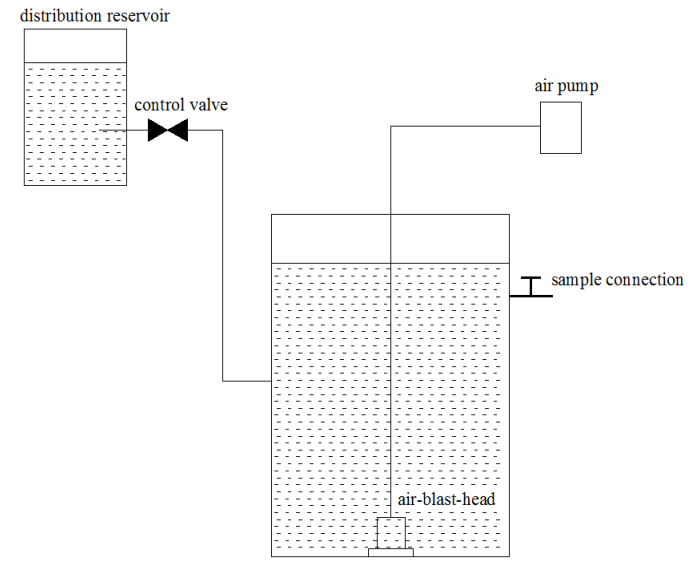

Figure 2. The test installation diagram of SBR (Sequencing Batch Reactor, SBR)

Table 1. Experimental device operating cycle of SBR (Sequencing Batch Reactor, SBR)

\begin{tabular}{c|c|c|c|c|c}
\hline Number & Inflow (min) & Stirring (h) & Aeration (h) & Still standing (min) & Effluent (min) \\
\hline 1 & 2 & 0 & 0 & 55 & 3 \\
2 & 2 & 1 & 2 & 55 & 3 \\
3 & 2 & 1 & 4 & 55 & 3 \\
4 & 2 & 1 & 6 & 55 & 3 \\
5 & 2 & 1 & 8 & 55 & 3 \\
\hline
\end{tabular}

In the simulated wastewater, glucose is used as carbon source, ammonium chloride as nitrogen source, and sodium dihydrogen phosphate as phosphorus source, and appropriate amount of trace elements are added to make $\mathrm{C}: \mathrm{N}: \mathrm{P}=100: 5: 1$. The initial values of COD, total nitrogen, total phosphorus and ammonia nitrogen are about 1000, $50,10,15 \mathrm{mg} \cdot \mathrm{ml}^{-1}$ and $\mathrm{pH}=7.0$, respectively. 


\section{Batch experiment}

The pellets with immobilized microbials were introduced into SBR to verify the contaminants removing ability in engineering application, while exploring the ability to remove contaminants in different conditions and the effects of dose-up and HRT on the ability to remove contaminants. Each reactor was filled with $2.0 \mathrm{~L}$ wastewater and added different dosages and types of pellets with immobilized microbial under different conditions. As a control, the other reactor was not added pellets. Then, placed the two reactions in $6 \pm 2{ }^{\circ} \mathrm{C}$ constant temperature incubator for five days. Samples were taken from the reactor to determine the concentration of COD, TP, NH3-N and TN in the influent and effluent per $6 \mathrm{~h}$. Triplicate of each set of experiments.

\section{Analytical method and statistical analysis}

The removal efficiencies of COD, TP, $\mathrm{NH}_{3}-\mathrm{N}$ and $\mathrm{TN}$ were measured to test the biotreatment performance of immobilized microbial pellets in the SBR system. COD was determined by potassium dichromate oxidation method, TP was determined by ammonium molybdate spectrophotometry, $\mathrm{NH}_{3}-\mathrm{N}$ was determined by phenol disulfonic acid spectrophotometry, and TN was determined by Peroxide of potassium sulfate ultraviolet spectro- photometry. The specific operation steps for the determination of each index are detailed in Waterand Wastewater monitoring analysis method. 4th Edition. Beijing: China Environmental Science Press, 2002, in Chinese. Optical density of bacteria suspension was measured at $600 \mathrm{~nm}$ using a double beam spectrophotometer (UV-T9, Puxi, Beijing), $\mathrm{pH}$ was measured with a $\mathrm{pH}$ meter (ZD-2, Leici). The data were processed with the excel software and plotted with Origin 8.6.

\section{Discussion and results}

\section{Optimization of immobilization conditions}

PVA with resistance to microbial decomposition characteristics such as good mechanical strength, which makes it suitable as immobilized microorganism carrier. Figure $3 a$ represents the effect of immobilized pellets with different PVA addition on $\mathrm{COD}, \mathrm{TP}, \mathrm{NH}_{3}-\mathrm{N}$ and $\mathrm{TN}$ removal. Immobilized pellets after joining PVA mold faster, and with the increase of the amount of PVA, the pellets present ascendant trend on the COD and $\mathrm{NH}_{3}-\mathrm{N}$ removal efficiency, but the removal efficiency of TP and TN decreased first, then increased slightly and then decreased. As shown in Figure 4, although the removal efficiency of TP reached the maximum without adding PVA $(\mathrm{PVA}(\mathrm{w} / \mathrm{v})=0 \%)$, considering that the mechanical strength of the pellets was too low at this time and had a certain viscosity, and the mechanical strength and molding speed were improved after adding PVA. When the PVA content was $4 \%$, the removal efficiency of COD TP, $\mathrm{NH}_{3}-\mathrm{N}$ and $\mathrm{TN}$ reached $50.57 \%, 58.41 \%, 48.95 \%$, and $46.43 \%$, respectively. The above conclusions indicated that the immobilized pellet with $4 \%$ PVA concentration was the most appropriate.

Calcium salt of SA is often used for embedding and fixation of microbial cells, and SA has a great impact on mechanical strength and mass transfer effect of immobilized pellets. The immobilized pellets without SA are difficult to form due to insufficient mechanical strength. After the addition of SA, the molding became easier, but when the SA concentration reached $3 \%$, the molding became difficult due to the increased viscosity. As can be seen from Figure $3 b$, it can be seen that $2 \%$ SA concentration is the 
best choice for the preparation of immobilized microbial pellets, and the removal efficiency of COD, TP, $\mathrm{NH}_{3}-\mathrm{N}$ and $\mathrm{TN}$ reaches $47.25 \%, 46.06 \%, 47.68 \%$ and $40.94 \%$, respectively.

The results of the best concentration of PVA and SV in immobilized microorganism carrier were similar to Ali et al.'s research (2015), which was use 6\% (w/v) PVA and $2 \%(\mathrm{w} / \mathrm{v}) \mathrm{SA}$ as the most appropriate mixture gel concentration in anammox biomass for meeting the criterion of rapid and successful start-up of anammox process.

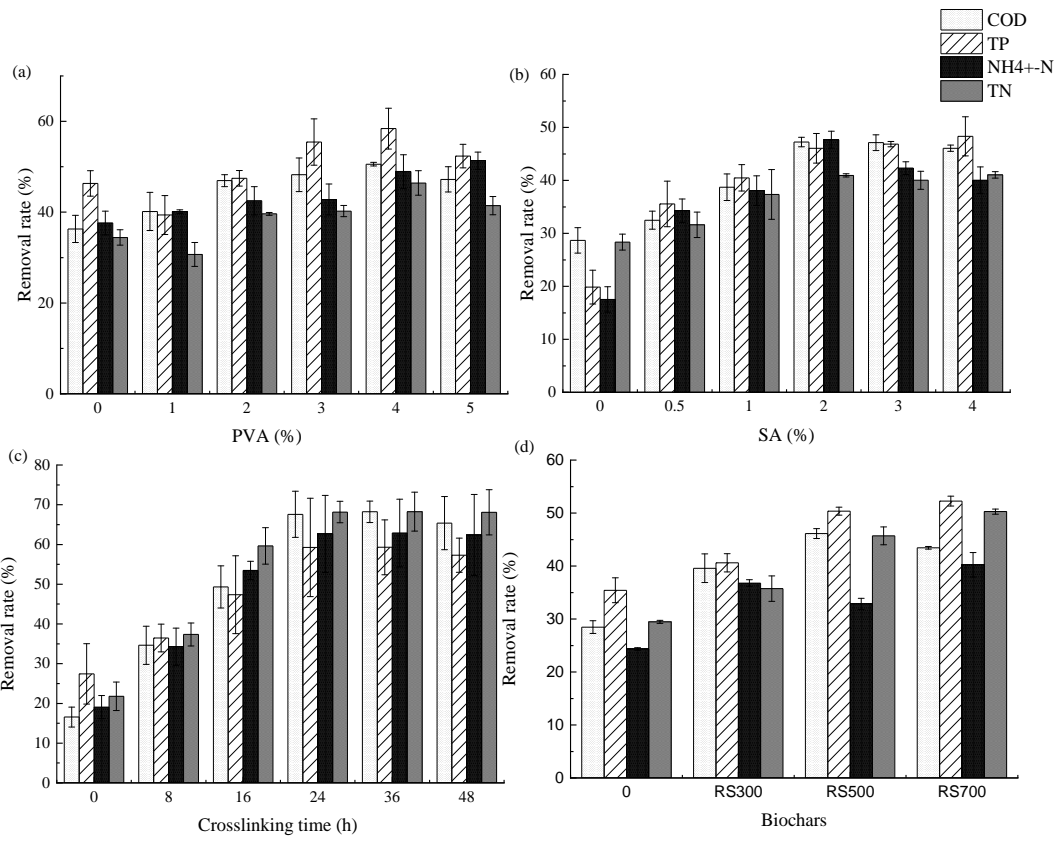

Figure 3. The removal efficiency of COD (chemical oxygen demand, COD), TP (total phosphorus, TP), NH3-N (ammonianitrogen, NH3-N) and TN (total nitrogen, TN) for different immobilized pellets, as (a), (b), (c) and (d) shows the effect of PVA (polyvinyl alcohol, PVA), SA (alginic acid sodium, SA), crosslinking time and biochars type on the SBR (Sequencing Batch Reactor, SBR)

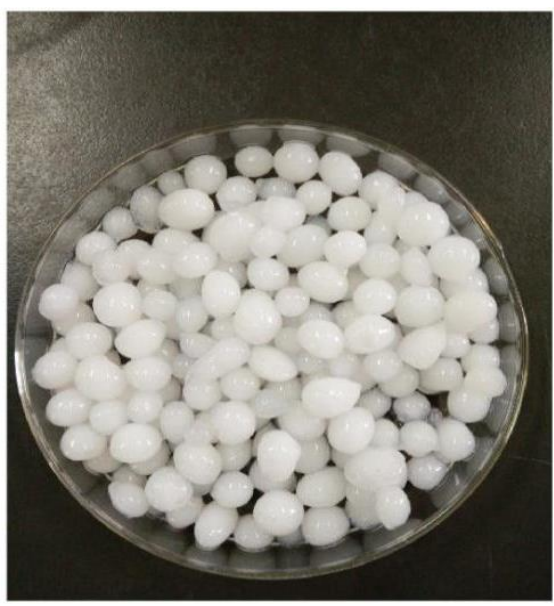

a,

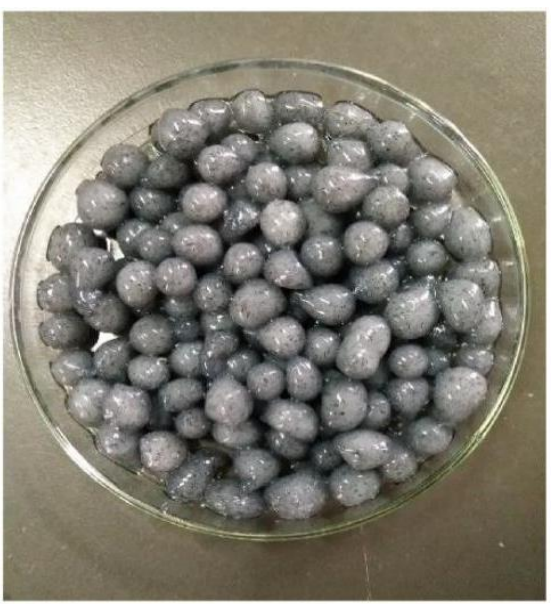

$\mathrm{b}$,

Figure 4. The picture of immobilized pellets ((a) shows pellets without biochar, (b) shows pellets added $R S 700)$ 
In order to explore the effect of immobilized microbial pellets prepared with different immobilization time, $\mathrm{COD}, \mathrm{TP}, \mathrm{NH}_{3}-\mathrm{N}$ and $\mathrm{TN}$ concentrations in simulated wastewater were monitored. It can be seen that with the increase of crosslinking time, the removal efficiency of $\mathrm{COD}, \mathrm{TP}, \mathrm{NH}_{3}-\mathrm{N}$ and $\mathrm{TN}$ of microbial immobilized pellets gradually increased. As can be seen from Figure 3c, the removal efficiency of COD, TP, and $\mathrm{NH}_{3}-\mathrm{N}$ reaches the maximum at $24 \mathrm{~h}(91.41 \%, 79.08 \%, 47.68 \%$ and $84.51 \%$, respectively). The removal rate of $\mathrm{TN}$ is relatively high, which reached $96.03 \%$. Thus the optimal immobilization time for microbial immobilized pellets is $24 \mathrm{~h}$, which was faster than Zhu et al.'s study (2009). In that research, the nitrite concentrations almost did not change from 39 hours to 49 hours at PVA-SA immobilized gel beads system because the ammonium was almost completely removed before 39 hours. As is shown in Figure 3c, the removal efficiency of $\mathrm{NH}_{3}-\mathrm{N}$ was lower than Zhu et al.'s study (2009), which may because of the reaction temperature and initial concentration.

To explore the removal rate of $\mathrm{COD}, \mathrm{TP}, \mathrm{NH}_{3}-\mathrm{N}$ and $\mathrm{TN}$ effects of immobilized pellets added biochar with different temperature, immobilized microbes pellets were added rice straw biochar $300^{\circ} \mathrm{C}(\mathrm{RS} 300), 500^{\circ} \mathrm{C}$ (RS500), $700^{\circ} \mathrm{C}$ (RS700) $0.4 \mathrm{~g}$, respectively, at the same time immobilized pellet without biochar was used as a control. It can be seen from Figure $3 d$ that the removal efficiency of COD, TP, $\mathrm{NH}_{3}-\mathrm{N}$ and TN were significantly improved after the addition of biochar RS700, which were achieved $99.42 \%, 98.24 \%, 94.23 \%$ and $99.01 \%$, respectively. The mechanical strength was relatively stable. Meanwhile, the experimental data showed that the removal efficiency of COD, TP, $\mathrm{NH}_{3}-\mathrm{N}$ and TN were RS700> RS500> RS300> 0. Removing of COD, TP, $\mathrm{NH}_{3}-\mathrm{N}$ and $\mathrm{TN}$ from water onto biochar occurs due to its high surface area and microporosity (Lou et al., 2011). The differences of removal efficiency results between $\mathrm{RS} 700, \mathrm{RS} 500, \mathrm{RS} 300$ were due to that biochars produced at $>400^{\circ} \mathrm{C}$ are more effective for organic contaminant sorption because of their high surface area and micropore development (Ahmad et al., 2012, 2014).

\section{Effect of different dosages and HRT on Sequencing Batch Reactor (SBR)}

To explore the effect of different dosages of immobilized microbe pellets on sewage treatment, the SBR reactor runs continuously for 5 days. The results showed an excellent sewage treatment efficiency of immobilized pellets added RS700. As shown in Figure 5, the removal efficiency of COD, TP, $\mathrm{NH}_{3}-\mathrm{N}$ and $\mathrm{TN}$ increased with the dose (0-30 mL).

Actually, when the dosage of mixed bacterial solutions was increased from $0 \mathrm{~mL}$ to $10 \mathrm{~mL}$, the removal efficiency of sewage in SBR was significantly improved. When the dosage was increased from $10 \mathrm{~mL}$ to $30 \mathrm{~mL}$, the purification efficiency was improved; but, the improvement was not significant. Apparently, each sewage index has the best removal efficiency when the bacteria dosage is $30 \mathrm{~mL}$, but the cost was too high to make it feasible. As can be seen from Figure 5, when the mixed bacterial liquid additive amount was $20 \mathrm{~mL}$, within hydraulic retention time $5 \mathrm{~d}$ and water temperature 6 to $8^{\circ} \mathrm{C}$, the removal efficiency of each index in SBR was gradually increased, eventually the removal rate of $\mathrm{COD}, \mathrm{TP}, \mathrm{NH}_{3}-\mathrm{N}$ and $\mathrm{TN}$ reached $80.89 \%, 59.80 \%, 77.60 \%$ and $58.28 \%$, respectively. From the perspective of operation cost and the efficaciousness of sewage treatment, $20 \mathrm{ml}$ should be selected as the best dosage of the mixed bacterial solutions for the SBR.

HRT usually plays a key role in the removal of pollutants in water, and explores the best HRT is one of the steps necessary to conduct an SBR experiment (Hamjinda et al., 
2017). In order to evaluate the effect of immobilized pellets with different HRT on sewage treatment, the SBR system was kept at 6 to $8^{\circ} \mathrm{C}$ when the dosage was $20 \mathrm{~mL}$. It can be seen in Figure 6 that the removal efficiency of each index changes with HRT. As the HRT increased from 0 to 3 day, the removal efficiencies of COD, TP, $\mathrm{NH}_{3}-\mathrm{N}$ and TN improved significantly. When HRT is increased from 3 days to 5 days, purification efficiency was improved. However, the improvement was not obvious. Considering the operating costs and experimental operation, 4 days should be selected as the best HRT for the SBR. When the HRT was 4 days, the removal rate of COD, TP, $\mathrm{NH}_{3}-\mathrm{N}$ and TN for the pellets reached $79.32 \%, 59.31 \%, 72.35 \%$, and $87.14 \%$, respectively.
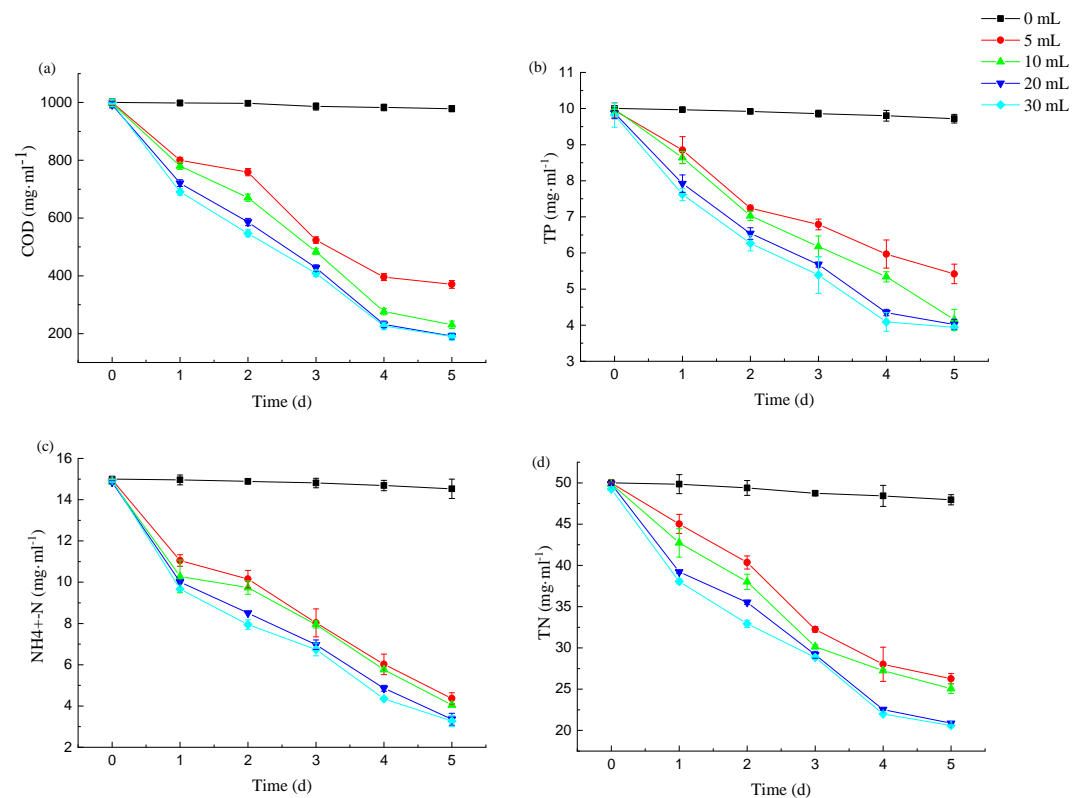

Figure 5. The concentration of COD (chemical oxygen demand, COD), TP (total phosphorus, $\mathrm{TP}$ ), $\mathrm{NH}_{3}-\mathrm{N}$ (ammonianitrogen, $\mathrm{NH} 3-\mathrm{N}$ ) and $\mathrm{TN}$ (total nitrogen, TN) changes with dosages in the SBR( as figure (a), (b), (c) and (d) shows the change of removal rate of COD, TP, NH3-N and $T N$ with the increase of dosage)

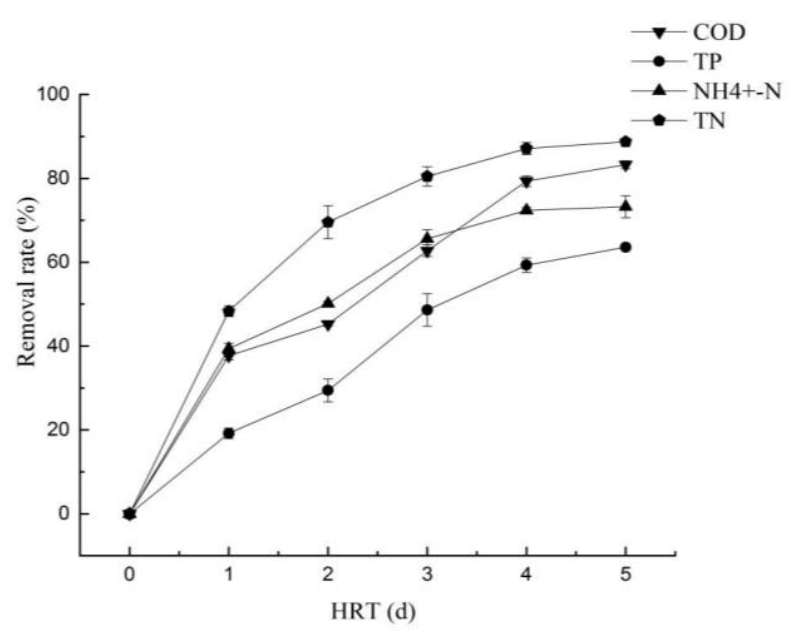

Figure 6. The concentration of COD (chemical oxygen demand, COD), TP (total phosphorus, $T P$ ), NH3-N (ammonianitrogen, NH3-N) and TN (total nitrogen, TN) changes with hydraulic retention time (HRT) in the SBR (Sequencing Batch Reactor, SBR) 


\section{Wastewater treatment dynamics equation}

Kinetic research could optimize the technology and methods of biochemical processes. In fact, the patterns of microbial degradation could be predicted by modeling kinetic degradation models and modern techniques to simulate degradation(Jou et al., 2008). Kinetic model was used to describe an aerobic granular sludge reactor, fed with a defined influent, capable of simultaneously removing COD, nitrogen and phosphate in one sequencing batch reactor (SBR). The model could describe the experimental data from the SBR sufficiently. Thus, the effect of process parameters on the nutrient removal rates could be reliably evaluated (Chung and Rittmann, 2007). In the SBR system, the degradation efficiency of immobilized microbial pellets to pollutants in sewage can be simulated by first-order kinetic equation:

$$
\begin{gathered}
\ln \frac{C_{e}}{C_{0}}=-k_{v} t \\
k_{v}=\frac{-1}{t} \ln \left(\frac{C_{0}}{C_{e}}\right)
\end{gathered}
$$

where $\mathrm{k}_{\mathrm{v}}$ is the contaminant volume removal rate constant, $\mathrm{d}^{-1}$; $\mathrm{Ce}$ and $\mathrm{C}_{0}$ are the influent and effluent concentration, $\mathrm{mg} \cdot \mathrm{ml}^{-1}$; $\mathrm{t}$ is the hydraulic retention time, $\mathrm{d}$.

According to the above kinetic model, the average effluent concentration of each contaminant in the SBR system was denoted as $\mathrm{C}_{\mathrm{e}}$, and the average influent concentration was denoted as $\mathrm{C}_{0} . \ln \left(\mathrm{C}_{0} / \mathrm{C}_{\mathrm{e}}\right)$ was taken as the ordinate, and $\mathrm{t}$ (time) as the abscissa. The $\ln \left(\mathrm{C}_{0} / \mathrm{C}_{\mathrm{e}}\right)$ of different dosage of bacteria and different hydraulic retention time (dosage of bacteria is $20 \mathrm{~mL}$ ) are taken as ordinate in the Figure 7 , Figure 8, respectively.

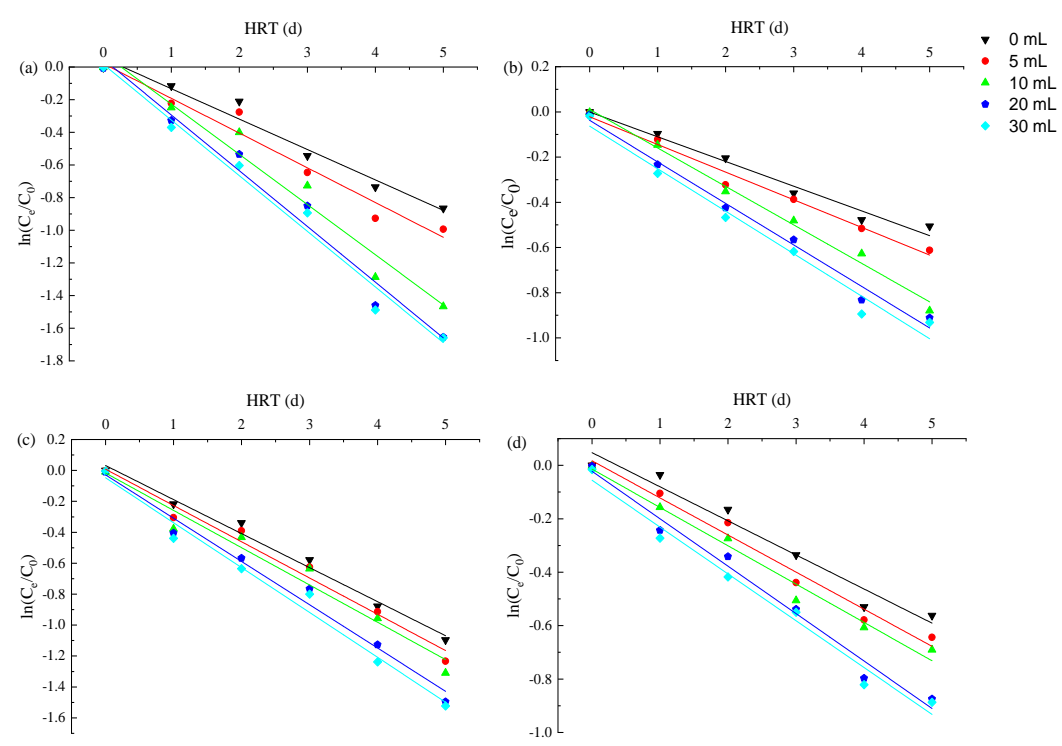

Figure 7. First-order degradation of organic matter with different dosage of immobilized pellets added RS700 in the SBR (Sequencing Batch Reactor, SBR) units operated under $6 \sim 8^{\circ} \mathrm{C}$, and $(a),(b),(c),(d)$ represent the time curves of COD (chemical oxygen demand, COD), TP (total phosphorus, TP), NH3-N (ammonianitrogen, NH3-N) and TN (total nitrogen, TN) 
The first-order kinetic model and $\mathrm{R}^{2}$ value of each contaminant with different dosage of immobilized pellets added RS700 in the SBR are shown in Table 2. And, the first-order kinetic model of organic matter with immobilized pellets added RS700 at different hydraulic retention time in the SBR are shown in Table 3. The measurement results of COD, TP, $\mathrm{NH}_{3}-\mathrm{N}$ and TN were substituted into equation (Eq.2) at HRT of 4 days, and $\mathrm{k}_{\mathrm{v}}$ was calculated as shown in Table 4.

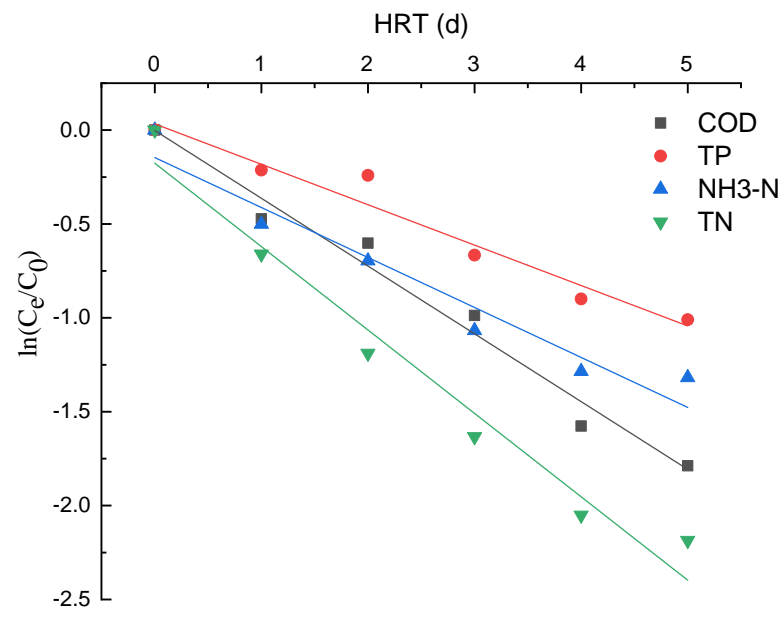

Figure 8. First-order degradation of organic matter with immobilized pellets added RS700 at different hydraulic retention time in the SBR (Sequencing Batch Reactor, SBR) units operated under $6 \sim 8{ }^{\circ} \mathrm{C}$

Table 2. First-order kinetics model and the $R 2$ value of removal with different dosage of immobilized pellets added RS700 in the SBR

\begin{tabular}{c|c|c|c|c|c|c|c}
\hline $\begin{array}{c}\text { Pollution } \\
\text { parameter }\end{array}$ & $\begin{array}{c}\text { Dosage } \\
(\mathbf{m L})\end{array}$ & $\begin{array}{c}\text { First-order kinetics } \\
\text { model }\end{array}$ & $\mathbf{R}^{\mathbf{2}}$ value & $\begin{array}{c}\text { Pollution } \\
\text { parameter }\end{array}$ & $\begin{array}{c}\text { Dosage } \\
(\mathbf{m L})\end{array}$ & $\begin{array}{c}\text { First-order kinetics } \\
\text { model }\end{array}$ & $\mathbf{R}^{\mathbf{2}}$ value \\
\hline \multirow{4}{*}{$\mathrm{COD}$} & 0 & $\mathrm{y}=-0.18632 \mathrm{x}+0.05374$ & 0.9629 & & 0 & $\mathrm{y}=-0.22013 \mathrm{x}+0.03185$ & 0.9841 \\
& 5 & $\mathrm{y}=-0.21281 \mathrm{x}+0.02113$ & 0.9535 & & 5 & $\mathrm{y}=-0.23455 \mathrm{x}+0.00806$ & 0.9729 \\
& 10 & $\mathrm{y}=-0.30757 \mathrm{x}+0.08038$ & 0.9579 & $\mathrm{NH}_{3}-\mathrm{N}$ & 10 & $\mathrm{y}=-0.24126 \mathrm{x}-0.0168$ & 0.9548 \\
& 20 & $\mathrm{y}=-0.34145 \mathrm{x}+0.04786$ & 0.9697 & & 20 & $\mathrm{y}=-0.27993 \mathrm{x}-0.02865$ & 0.9772 \\
& 30 & $\mathrm{y}=-0.34099 \mathrm{x}+0.01643$ & 0.9761 & & 30 & $\mathrm{y}=-0.29023 \mathrm{x}-0.04761$ & 0.9770 \\
\hline \multirow{4}{*}{$\mathrm{TP}$} & 0 & $\mathrm{y}=-0.10939 \mathrm{x}-6.00345 \mathrm{E}-4$ & 0.9727 & & 0 & $\mathrm{y}=-0.12763 \mathrm{x}+0.04747$ & 0.9521 \\
& 5 & $\mathrm{y}=-0.12236 \mathrm{x}-0.0217$ & 0.9793 & & 5 & $\mathrm{y}=-0.1389 \mathrm{x}+0.01707$ & 0.9745 \\
& 10 & $\mathrm{y}=-0.17028 \mathrm{x}+0.01092$ & 0.9889 & $\mathrm{TN}$ & 10 & $\mathrm{y}=-0.14349 \mathrm{x}-0.0141$ & 0.9771 \\
& 20 & $\mathrm{y}=-0.18371 \mathrm{x}-0.03745$ & 0.9848 & & 20 & $\mathrm{y}=-0.17757 \mathrm{x}-0.02229$ & 0.9795 \\
& 30 & $\mathrm{y}=-0.18812 \mathrm{x}-0.06308$ & 0.9711 & & 30 & $\mathrm{y}=-0.17531 \mathrm{x}-0.05582$ & 0.9756 \\
\hline
\end{tabular}

By monitoring the SBR operation system, the degradation efficiency of pollutants was improved under conditions of different amount of bacteria and different hydraulic residence time. As Figure 7 and Figure 8 showed that the removal kinetics of contaminants in the SBR conforms to the first-order kinetic model. The volume degradation rate $\mathrm{k}_{\mathrm{v}}$ represents the treatment efficiency of the contaminants. Mixed Psychotropic bacterial flora had a noticeably high disposal rate for pollutants at a HRT of 4 days. Furthermore, the degradation rates of $\mathrm{COD}, \mathrm{TP}, \mathrm{NH}_{3}-\mathrm{N}$ and $\mathrm{TN}$ significantly increased as the dosage of bacteria was increased. The $\mathrm{R}^{2}$ of each $\mathrm{k}_{\mathrm{v}}$ reached $0.78,0.95$, 0.98, 0.91. Similarly, Tang et al. (2018) added a mixed of Psychrotrophic bacteria 
strains in an integrated vertical-flow constructed wetland at a temperature of $(6 \pm 1)^{\circ} \mathrm{C}$, which had a high disposal rate for pollutants at a HRT of 5 days and the degradation rates of $\mathrm{COD}, \mathrm{NH}_{3}-\mathrm{N}, \mathrm{NO}_{2}{ }^{-}-\mathrm{N}, \mathrm{NO}_{3}{ }^{-}-\mathrm{N}, \mathrm{TN}$ and TP significantly increased as the dosage of bacteria was increased.

Table 3. First-order kinetics model and the $R^{2}$ value of removal with different dosage of immobilized pellets added RS700 in the SBR

\begin{tabular}{c|c|c}
\hline Pollution parameter & First-order kinetics model & $\mathbf{R}^{2}$ value \\
\hline $\mathrm{COD}$ & $\mathrm{y}=-0.36096 \mathrm{x}-0.00205$ & 0.9712 \\
$\mathrm{TP}$ & $\mathrm{y}=-0.21519 \mathrm{x}+0.0331$ & 0.9475 \\
$\mathrm{NH}_{3}-\mathrm{N}$ & $\mathrm{y}=-0.26618 \mathrm{x}-0.14604$ & 0.9283 \\
$\mathrm{TN}$ & $\mathrm{y}=-0.44416 \mathrm{x}-0.17614$ & 0.9587 \\
\hline
\end{tabular}

Table 4. $k v$ in the pseudo-first order reaction of pollutants removal at HRT of 4 days in the SBR

\begin{tabular}{c|c|c|c|c}
\hline \multirow{2}{*}{$\begin{array}{c}\text { Dosage of immobilized } \\
\text { pellets/mL }\end{array}$} & COD & TP & KH3-N & TN \\
\cline { 2 - 5 } & 0.184 & 0.120 & 0.220 & 0.133 \\
5 & 0.232 & 0.129 & 0.228 & 0.145 \\
10 & 0.322 & 0.157 & 0.239 & 0.152 \\
20 & 0.365 & 0.208 & 0.282 & 0.199 \\
30 & 0.372 & 0.224 & 0.309 & 0.205 \\
R2 & 0.78 & 0.95 & 0.98 & 0.91 \\
\hline
\end{tabular}

\section{Conclusions}

1) For immobilized microbe pellets, the optimal optimization conditions were reached when: the mass fraction of SA was $2 \%$, the amount of PVA was $4 \%$, and cross-linking time $24 \mathrm{~h}$, the best biochar added was RS700. The results of the immobilization experiment provide a methodological support for improving the sewage treatment effect under low temperature conditions.

2) Mixed bacteria under the condition of optimization system for immobilized pellets was added to the continuous running of SBR process, $20 \mathrm{~mL}$ bacteria suspension of immobilized pellets could use to test the best dosage through the experiment monitoring. Under the optimal addition condition, the longer the HRT in the SBR process, the better the treatment effect would be. In a comprehensive consideration, the optimal HRT was $4 \mathrm{~d}$, and the removal efficiency of COD, TP, $\mathrm{NH}_{3}-\mathrm{N}$ and TN under the best dosage was reached at $76.79 \%, 56.50 \%, 67.60 \%$ and $54.92 \%$ at 4 days, respectively.

3) In the SBR process, the degradation efficiency of immobilized pellets for each pollutant $\mathrm{COD}, \mathrm{TP}, \mathrm{NH}_{3}-\mathrm{N}$ and $\mathrm{TN}$ in the SBR conforms to the first-order kinetic model.

4) The results of this study provide a theoretical foundation and scientific support for the use of SBR in wastewater treatment, and may have great significance in solving the increasingly severe water pollution problem in China. In future research, the selection of microbial species and the optimization of immobilization conditions should be carried out for different types of sewage. At the same time, new materials should be considered as additives to promote the study of microbial activity. 
Acknowledgements. The authors gratefully thank the financial support provided by the National Natural Science Foundation of China (No. 31700433; No. 31672314).

\section{REFERENCES}

[1] Ahmad, M., Lee, S. S., Dou, X. M., Mohan, D., Sung, J-K., Yang, J. E., Ok, Y. S. (2012): Effects of pyrolysis temperature on soybean stover- and peanut shell-derived biochar properties and TCE adsorption in water. - Bioresource Technology 118: 536-544. doi: 10.1016/j.biortech. 2012.05.042.

[2] Ahmad, M., Rajapaksha, A. U., Lim, J. E., Zhang, M., Bolan, N., Mohan, D., Vithanage, M., Lee, S. S., Ok, Y. S. (2014): Biochar as a sorbent for contaminant management in soil and water: A review. - Chemosphere 99: 19-33. doi: 10.1016/j.chemosphere.2013.10.071.

[3] Ali, M., Oshiki, M., Rathnayake, L., Ishii, S., Satoh, H., Okabe, S. (2015): Rapid and successful start-up of anammox process by immobilizing the minimal quantity of biomass in PVA-SA gel beads. - Water Research 79: 147-157. doi: 10.1016/j.watres.2015.04.024.

[4] Argun, M. E., Dursun, S., Karatas, M. (2009): Removal of $\mathrm{Cd}(\mathrm{II}), \mathrm{Pb}(\mathrm{II}), \mathrm{Cu}(\mathrm{II})$ and $\mathrm{Ni}(\mathrm{II})$ from water using modified pine bark. - Desalination 249(2): 519-527. doi: 10.1016/j.desal.2009.01.020.

[5] Bisht, D., Yadav, S. K., Darmwal, N. S. (2013): Optimization of immobilization conditions by conventional and statistical strategies for alkaline lipase production by Pseudomonas aeruginosa mutant cells: Scale-up at bench-scale bioreactor level. - Turkish Journal of Biology 37(4): 392-404. doi: 10.3906/biy-1209-19.

[6] Chen, J., Hu, Y., Zhang, L., Huang, W., Sun, J. (2017): Bacterial community shift and improved performance induced by in situ preparing dual graphene modified bioelectrode in microbial fuel cell. - Bioresource Technology 238: 273-280. doi: 10.1016/j.biortech.2017.04.044.

[7] Chung, J., Rittmann, B. E. (2007): Trichloroethane and Chloroform Using a Hydrogen-Based Membrane Biofilm Reactor. - Biotechnology 97(1): 52-60. doi: 10.1002/bit.

[8] Ding, D., Feng, C. P., Jin, Y. X., Hao, C. B., Zhao, Y. X., Suemura, T. (2011): Domestic sewage treatment in a sequencing batch biofilm reactor (SBBR) with an intelligent controlling system. - Desalination 276(1-3): 260-265. doi: 10.1016/j.desal.2011.03.059.

[9] Dutta, A., Sarkar, S. (2015): Sequencing Batch Reactor for Wastewater Treatment: Recent Advances. - Current Pollution Reports 1(3): 177-190. doi: 10.1007/s40726-015-0016-y.

[10] Fu, D., Singh, R. P., Yang, X., Ojha, C. S. P., Surampalli, R. Y., Kumar, A. J. (2018): Sediment in-situ bioremediation by immobilized microbial activated beads: Pilot-scale study. - Journal of Environmental Management 226(July): 62-69. doi: 10.1016/j.jenvman.2018.08.021.

[11] Gundogdu, A., Ozdes, D., Duran, C., Bulut, V. N., Soylak, M., Senturk, H. B. (2009): Biosorption of $\mathrm{Pb}$ (II) ions from aqueous solution by pine bark (Pinus brutia Ten.). Chemical Engineering Journal 153(1-3): 62-69. doi: 10.1016/j.cej.2009.06.017.

[12] Hachicha, S., Cegarra, J., Sellami, F., Hachicha, R., Drira, N., Medhioub, K., Ammar, E. (2009): Elimination of polyphenols toxicity from olive mill wastewater sludge by its co-composting with sesame bark. - Journal of Hazardous Materials 161(2-3): 1131-1139. doi: 10.1016/j.jhazmat.2008.04.066.

[13] Hamjinda, N. S., Chiemchaisri, W., Chiemchaisri, C. (2017): Upgrading two-stage membrane bioreactor by bioaugmentation of Pseudomonas putida entrapment in PVA/SA gel beads in treatment of ciprofloxacin. - International Biodeterioration and Biodegradation 119: 595-604. doi: 10.1016/j.ibiod.2016.10.020. 
[14] He, J., Zhang, W., Ren, X. H., Xing, L. F., Chen, S., Wang, C. (2019): Preparation of Different Activated Sludge Immobilized Carriers and Their Organic Wastewater Treatment Performance by Microbial Community. - Environmental Engineering Science 36(5): 604-613. doi: 10.1089/ees.2018.0295.

[15] Jou, C. J., Chen, S. W., Kao, C. M., Lee, C. L. (2008): Assessing the efficiency of a constructed wetland using a first-order biokinetic model. - Wetlands 28(1): 215-219. doi: 10.1672/07-60.1.

[16] Khan, N. A., Ahmed, S., Islamia, J. M. (2019): Review on SBR Technology of Industrial Wastewater treatment.

[17] Kulkarni, P. (2013): Nitrophenol removal by simultaneous nitrification denitrification (SND) using $\mathrm{T}$. pantotropha in sequencing batch reactors (SBR). - Bioresource Technology 128: 273-280. doi: 10.1016/j.biortech.2012.10.054.

[18] Lim, J. W., Seng, C. E., Lim, P. E., Ng, S. L., Ahmad Sujari, A. N. (2011): Nitrogen removal in moving bed sequencing batch reactor using polyurethane foam cubes of various sizes as carrier materials. - Bioresource Technology 102(21): 9876-9883. doi: 10.1016/j.biortech.2011.08.014.

[19] Liu, G. H., Ye, Z. F., Tong, K., Zhang, Y. H. (2013): Biotreatment of heavy oil wastewater by combined upflow anaerobic sludge blanket and immobilized biological aerated filter in a pilot-scale test. - Biochemical Engineering Journal 72: 48-53. doi: 10.1016/j.bej.2012.12.017.

[20] Lou, L., Wu, B., Wang, L., Luo, L., Xu, X., Hou, J., Xun, B., Hu, B., Chen, Y. (2011): Sorption and ecotoxicity of pentachlorophenol polluted sediment amended with rice-straw derived biochar. - Bioresource Technology 102(5): 4036-4041. doi: 10.1016/j.biortech.2010.12.010.

[21] Marshall, W. E., Johns, M. M. (1996): Agricultural by-products as metal adsorbents: Sorption properties and resistance to mechanical abrasion. - Journal of Chemical Technology and Biotechnology 66(2): 192-198. doi:10.1002/(SICI)1097-4660(199606) 66:2<192::AID-JCTB489>3.0.CO;2-C.

[22] Mei, Y. Z., Huang, P. W., Liu, Y., He, W., Fang, W. W. (2016): Cold stress promoting a psychrotolerant bacterium Pseudomonas fragi P121 producing trehaloase. - World Journal of Microbiology and Biotechnology 32(8): 1-9. doi: 10.1007/s11274-016-2097-1.

[23] Nguyen, L. M. (2000): Organic matter composition, microbial biomass and microbial activity in gravel-bed constructed wetlands treating farm dairy wastewaters. - Ecological Engineering 16(2): 199-221. doi: 10.1016/S0925-8574(00)00044-6.

[24] Popple, T., Williams, J. B., May, E., Mills, G. A., Oliver, R. (2016): Evaluation of a sequencing batch reactor sewage treatment rig for investigating the fate of radioactively labelled pharmaceuticals: Case study of propranolol. - Water Research 88: 83-92. doi: 10.1016/j.watres.2015.09.033.

[25] Rao, J. R., Viraraghavan, T. (2002): Biosorption of phenol from an aqueous solution by Aspergillus niger biomass. - Bioresource Technology 85(2): 165-171. doi: 10.1016/S0960-8524(02)00079-2.

[26] Shen, J., Duvnjak, Z. (2005): Adsorption isotherms for cupric and cadmium ions on corncob particles. - Separation Science and Technology 40(7): 1461-1481. doi: 10.1081/SS-200053319.

[27] Showkat, U., Najar, I. A. (2019): Study on the efficiency of sequential batch reactor (SBR)-based sewage treatment plant. - Applied Water Science 9:2. doi: 10.1007/s13201-018-0882-8.

[28] Tang, M., Li, Z., Yang, Y., Chen, J., Jiang, J. (2018): Effects of the inclusion of a mixed Psychrotrophic bacteria strain for sewage treatment in constructed wetland in winter seasons. - Royal Society Open Science 5(4). doi: 10.1098/rsos.172360.

[29] Van Wyk, J. P. H. (1997): Cellulose hydrolysis and cellulase adsorption after pretreatment of cellulose materials. - Biotechnology Techniques 11(6): 443-445. doi: 10.1023/A:1018485226767. 
[30] Vázquez, G., Alonso, R., Freire, S., González-Álvarez, J., Antorrena, G. (2006): Uptake of phenol from aqueous solutions by adsorption in a Pinus pinaster bark packed bed. Journal of Hazardous Materials 133(1-3): 61-67. doi: 10.1016/j.jhazmat.2004.12.041.

[31] Zhao, Q., Ye, Z., Zhang, M. (2010): Treatment of 2,4,6-trinitrotoluene (TNT) red water by vacuum distillation. - Chemosphere 80(8): 947-950. doi:10.1016/j.chemosphere.2010. 05.004 .

[32] Zhu, G. L., Hu, Y. Y., Wang, Q. R. (2009): Nitrogen removal performance of anaerobic ammonia oxidation co-culture immobilized in different gel carriers. - Water Science and Technology 59(12): 2379-2386. doi: 10.2166/wst.2009.293. 